\title{
Management of HIV Infection during Pregnancy in the United States: Updated Evidence-Based Recommendations and Future Potential Practices
}

\author{
Bassam H. Rimawi, ${ }^{1}$ Lisa Haddad, ${ }^{2}$ Martina L. Badell, ${ }^{3}$ and Rana Chakraborty ${ }^{4}$ \\ ${ }^{1}$ School of Medicine, Department of Gynecology and Obstetrics, Division of Maternal Fetal Medicine and \\ Reproductive Infectious Diseases, Emory University, 550 Peachtree Street, Atlanta, GA 30308, USA \\ ${ }^{2}$ School of Medicine, Department of Gynecology and Obstetrics, Division of Family Planning, Emory University, \\ 550 Peachtree Street, Atlanta, GA 30308, USA \\ ${ }^{3}$ School of Medicine, Department of Gynecology and Obstetrics, Division of Maternal Fetal Medicine, Emory University, \\ 550 Peachtree Street, Atlanta, GA 30308, USA \\ ${ }^{4}$ School of Medicine, Department of Pediatrics, Division of Infectious Diseases, Emory University, 2015 Uppergate Drive, \\ NE, Atlanta, GA 30322, USA
}

Correspondence should be addressed to Bassam H. Rimawi; bassamrimawi@yahoo.com

Received 23 February 2016; Revised 8 June 2016; Accepted 16 June 2016

Academic Editor: Bryan Larsen

Copyright (C 2016 Bassam H. Rimawi et al. This is an open access article distributed under the Creative Commons Attribution License, which permits unrestricted use, distribution, and reproduction in any medium, provided the original work is properly cited.

All HIV-infected women contemplating pregnancy should initiate combination antiretroviral therapy (cART), with a goal to achieve a maternal serum HIV RNA viral load beneath the laboratory level of detection prior to conceiving, as well as throughout their pregnancy. Successfully identifying HIV infection during pregnancy through screening tests is essential in order to prevent in utero and intrapartum transmission of HIV. Perinatal HIV transmission can be less than $1 \%$ when effective cART, associated with virologic suppression of HIV, is given during the ante-, intra-, and postpartum periods. Perinatal HIV guidelines, developed by organizations such as the World Health Organization, American College of Obstetricians and Gynecologists, and the US Department of Health and Human Services, are constantly evolving, and hence the aim of our review is to provide a useful concise review for medical providers caring for HIV-infected pregnant women, summarizing the latest and current recommendations in the United States.

\section{Introduction}

Neonatal HIV infections are a result of transmission from a mother to her unborn fetus in utero, or during the intrapartum period, or postpartum secondary to breastfeeding [1]. In the US, perinatal transmission has been reduced to less than $1 \%$ in many states, reflecting implementation of key interventions during pregnancy, including initiating cART to suppress viral load beneath the level of detection and avoidance of breastfeeding during the postpartum period [1, 2]. Perinatal HIV guidelines in the US are constantly evolving. Here, we present a concise review outlining the latest perinatal recommendations, as well as potential future practices for medical providers caring for HIV-infected pregnant women.

\section{Incidence of Perinatal HIV Transmission}

Globally, without intervention, the cumulative in utero, intrapartum, and postpartum HIV transmission rate is approximately $35-40 \%$ [2]. In breastfeeding populations, postpartum HIV transmission through breastfeeding contributes about $40-45 \%$ of all mother-to-child transmissions (http://www.unaids.org/en/media/unaids/contentassets/ documents/unaidspublication/2011/20110609_JC2137_Global -Plan-Elimination-HIV-Children_en.pdf). Maternal HIV viral load level is by far the most predictive factor for perinatal HIV transmission. Higher HIV viral loads correlate with a greater risk of perinatal transmission, although transmission can occur with any viral load, even when the systemic plasma 
viral load is beneath the level of detection [3]. Globally, the transmission rates for HIV can be reduced to less than $1 \%$ in pregnant women being compliant on their cART with virologic suppression and other perinatal recommendations $[4,5]$. Without any intervention, this transmission rate is closer to 25\% [2]. Among Hispanic/Latino and Caucasian women, the rates of HIV transmission have remained relatively stable in $2012(<2 \%$ and $1 \%$, resp.) $[1,2]$.

\section{Preconception Counseling}

All reproductively aged HIV-infected women should seek counseling prior to contemplating pregnancy, so that a detailed discussion on childbearing can be established. A key focus of discussions should include prevention of motherto-child transmission (MTCT) of HIV, by initiation or continuation of an appropriately selected cART regimen [6], compliance with these medications during pregnancy and the postpartum period, and identifying potential barriers [7] that may affect postpartum retention in HIV care $[8,9]$. The ability to successfully achieve maximal viral suppression before conception and throughout pregnancy is by far the most predictive means of achieving the lowest risk of potential MTCT [6]. Preconception counseling should be aimed at identifying women who may be victims of intimate partner violence, depression, and other psychological or psychiatric illnesses that may serve as barriers to prevention of MTCT and to treat and gain control of these conditions prior to contemplating pregnancy [10]. These strategies will not only result in safer conception and better compliance with cART but also result in better pregnancy outcomes [10].

\section{HIV-Concordant and Discordant Couples}

Consultation should include an expert in perinatal medicine and/or an experienced specialist who cares for HIV infected individuals [11]. With discordant couples that involve HIVinfected women, conception via timed artificial insemination is the safest option either via self-insemination or via intrauterine insemination [12]. When the discordant couple involves an HIV-infected male, the safest option for pregnancy is via insemination with donor HIV negative sperm. If the couple does not desire donor sperm, semen analysis is recommended prior to attempted pregnancy to avoid unnecessary exposure to genital fluid if semen abnormalities exist. Also sperm preparation techniques followed by intrauterine insemination or in vitro fertilization may reduce exposure risks [12].

\section{Antepartum Care of HIV-Infected Women}

Pitfalls and missed opportunities in healthcare delivery include failure of medical providers to screen pregnant women for HIV, ideally in the first trimester or at their first prenatal visit [7]. Transmission events are often documented in pregnant women who present with limited or no prenatal care, and those who decline HIV screening during pregnancy [13]. Pregnant women who have not previously had HIV screening and present to a labor and delivery suite in labor urgently require rapid HIV testing at the time of admission [14]. If a positive rapid HIV test is noted, and these patients are deemed to be in active labor or delivery is warranted for other obstetrical indications, then immediately implementing interventions to reduce intrapartum HIV transmission is recommended, which includes a combination of maternal administration of at least 3 hours of intravenous zidovudine therapy prior to a cesarean delivery and postnatal infant prophylaxis with a dual ARV combination regimen of zidovudine and nevirapine [15]. Awaiting laboratory confirmation should not delay these urgent interventions [11].

For known positive mothers, HIV RNA quantitative viral loads should be assessed monthly; however, some medical providers may consider wider interval blood draws to every 2 months, in those pregnant women who have consistently had a suppressed HIV-1 RNA viral load beneath the level of detection while on effective cART [16]. Figure 1 illustrates algorithmic management of HIV during pregnancy.

\section{The Diagnosis of HIV during Pregnancy}

A positive screening test with traditional HIV testing modalities, either with an HIV 1/2 Antigen/Antibody test or with a Fourth Generation test with reflexes essentially establishes a diagnosis of HIV infection [17]. Newer testing modalities include reflex Multispot rapid HIV testing, which includes a combined HIV-1/HIV-2 rapid test to distinguish between HIV-1 and 2 infection; hence, a positive Multispot test confirms a diagnosis of HIV $[17,18]$. However, if the Multispot test is negative, additional reflex testing for establishing a diagnosis of HIV infection includes proceeding with a polymerase chain reaction (PCR) test [18]. The sensitivity and specificity of rapid HIV testing are close to $100 \%$, while the positive predictive value (PPV) depends on the prevalence of the disease in the general population being tested $[19,20]$. In populations in which the HIV prevalence is low, a lower PPV is noted [19]. Table 1 demonstrates the different diagnostic tests that are available for establishing a diagnosis of HIV in pregnant women.

\section{Coinfection Screening and Vaccination Recommendations}

In addition to routine prenatal labs obtained during the first trimester, or at entry into prenatal care, which already includes the assessment of hepatitis B and syphilis, screening for hepatitis $\mathrm{C}$ coinfection is recommended for HIV positive women [16]. Those who have a negative hepatitis B surface antibody status should receive hepatitis $B$ vaccine series during pregnancy, regardless of which trimester they are in, as well as screening for immunity to hepatitis A, as a combination vaccine for hepatitis B and hepatitis A exists, formerly known as Twinrex [21]. Patients who are coinfected with these other viral entities should seek consultation with HIV and hepatitis-experienced medical provider(s). For patients with hepatitis B infection, all newborn infants should receive both the hepatitis B vaccine series and hepatitis B immune globulin 
TABLE 1: Testing modalities for diagnosing HIV in pregnancy*.

\begin{tabular}{|c|c|c|c|c|c|}
\hline HIV tests & What they test for & Window period & Available results & Sensitivity & Specificity \\
\hline ELISA & HIV antibodies & 3 Months & 2 days -2 weeks & $>99 \%$ & $>98 \%$ \\
\hline Antigen test (p24) & P24 viral proteins & 11 days -1 month & 2 days-1 week & $90 \%$ & $100 \%$ \\
\hline 4 th generation tests & Antibodies and p24 & 11 days -1 month & 2 days -2 weeks & $>99.7 \%$ & $>99.3 \%$ \\
\hline PCR/NAAT tests & Genetic material of HIV & 12 days & 2 days-1 week & $>99 \%$ & $>99 \%$ \\
\hline Rapid test & Antibodies & 3 Months & Within 20 minutes & $>99 \%$ & $>98 \%$ \\
\hline
\end{tabular}

*AIDSinfo. Recommendations for use of antiretroviral drugs in pregnant HIV-1-infected women for maternal health and interventions to reduce perinatal HIV transmission in the United States. HHS panel on treatment of HIV-infected pregnant women and prevention of perinatal transmission, a working group of the office of AIDS research advisory council (OARAC), 2015, http://aidsinfo.nih.gov/guidelines.

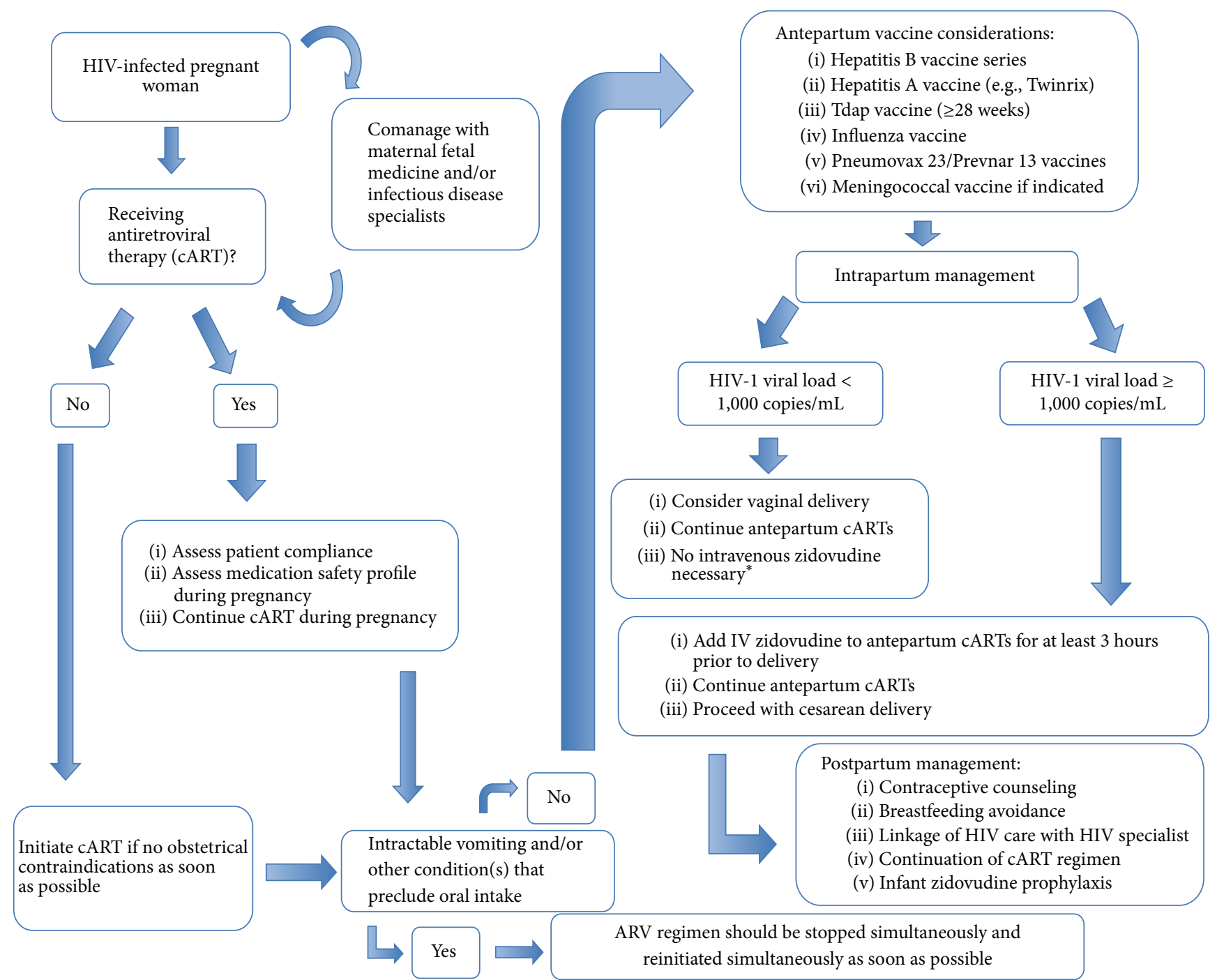

FIGURE 1: Algorithm for management of HIV during pregnancy. ${ }^{*}$ Intravenous (IV) zidovudine is not required for HIV-infected women who are compliant with cART and who have an HIV-viral load < 1000 copies/mL at the time of delivery. HIV: human immunodeficiency virus, CART: combination antiretroviral therapy, PO: per os (by mouth), CBC: complete blood count, CMP: complete metabolic panel, CD4: cluster of differentiation 4 , and $\mathrm{mL}$ : milliliter.

preferably within 12 hours after delivery, regardless of the maternal hepatitis B viral load [22, 23].

In addition to vaccination against hepatitis $A$ and $B$ during pregnancy, additional vaccines to offer HIV-infected women during pregnancy should include the influenza vaccine (inactivated) during the influenza season, which can be offered to unvaccinated pregnant women during any trimester of pregnancy, as well as combined diphtheria, tetanus, and pertussis (Tdap) vaccine around 28-36 weeks of gestation [23]. Additional vaccines that may be given to HIV-infected pregnant women include Pneumovax 23 (23valent pneumococcal polysaccharide) vaccine and Prevnar 13 
TABLE 2: Treatment regimens for HIV-infected pregnant women.

\begin{tabular}{|c|c|c|}
\hline Brand name & Preparation & Comments \\
\hline \multicolumn{3}{|c|}{ Preferred regimens } \\
\hline \multicolumn{3}{|c|}{ Two-NRTI backbone } \\
\hline Trizivir & $\mathrm{ABC} / 3 \mathrm{TC}$ & $\begin{array}{l}\text { Patients with an HIV RNA viral load > } \\
\text { 100,000 copies/mL should not receive a } \\
\text { combination therapy consisting of } \\
\text { ABC/3TC with ATV/ritonavir or } \\
\text { efavirenz. }\end{array}$ \\
\hline Truvada & TDF/FTC or 3TC & $\begin{array}{l}\text { TDF-based dual NRTI combinations } \\
\text { should be used with caution in patients } \\
\text { with renal insufficiency. }\end{array}$ \\
\hline Combivir & ZDV/3TC & $\begin{array}{l}\text { NRTI combination therapy requires twice } \\
\text { daily administration and increases } \\
\text { potential for hematologic toxicities. }\end{array}$ \\
\hline \multicolumn{3}{|c|}{ Protease inhibitor regimens } \\
\hline Reyataz & ATV/r plus a two-NRTI backbone & Maternal hyperbilirubinemia. \\
\hline Prezista & $\mathrm{DRV} / \mathrm{r}$ plus a two-NRTI backbone & Must be used twice daily in pregnancy. \\
\hline \multicolumn{3}{|c|}{ NNRTI regimen } \\
\hline Efavirenz & EFV plus a two-NRTI backbone* & $\begin{array}{l}\text { Concern because of birth defects seen in } \\
\text { primate study, unclear risk in humans. }\end{array}$ \\
\hline \multicolumn{3}{|c|}{ Integrase inhibitor regimen } \\
\hline Raltegravir & RAL plus a two-NRTI backbone & $\begin{array}{l}\text { Rapid viral load reduction. Twice-daily } \\
\text { dosing required. }\end{array}$ \\
\hline \multicolumn{3}{|c|}{ Alternative regimens } \\
\hline \multicolumn{3}{|c|}{ Protease inhibitor regimens } \\
\hline Kaletra & $\mathrm{LPV} / \mathrm{r}$ & $\begin{array}{l}\text { More nausea than preferred regimens. } \\
\text { Twice-daily administration in pregnancy. }\end{array}$ \\
\hline \multicolumn{3}{|c|}{ NNRTI regimens } \\
\hline Complera & RPV/TDF/FTC (or RPV plus a two-NRTI backbone) & $\begin{array}{l}\text { RPV not recommended with } \\
\text { pretreatment HIV RNA }>100,000 \\
\text { copies/mL or CD } 4 \text { cell count }<200 \\
\text { cells } / \mathrm{mm}^{3} \text {. Do not use with PPIs. PK data } \\
\text { available in pregnancy but relatively little } \\
\text { experience with use in pregnancy. } \\
\text { Available in co formulated single-pill } \\
\text { once daily regimen. }\end{array}$ \\
\hline
\end{tabular}

NRTI: nucleoside or nucleotide reverse transcriptase inhibitor, NNRTI: nonnucleoside or nonnucleotide reverse transcriptase inhibitor, ABC: abacavir, 3TC: lamivudine, TDF: tenofovir disoproxil, FTC: emtricitabine, ZDV: zidovudine, ATV: atazanavir, r: ritonavir (boosted regimen), DRV: darunavir, ${ }^{*}$ EFV: efavirenz, recommended to be started after 8 weeks of gestation, RAL: raltegravir, LPV: lopinavir, and RPV: rilpivirine.

(13-valent pneumococcal conjugate) vaccine [23]. Vaccines that should not be given during pregnancy and postponed until the postpartum period include vaccination against varicella, zoster, human papillomavirus (HPV) and measles, mumps, and rubella (MMR), if testing results are equivocal or nonimmune [23]. At this time, vaccination with serogroup B meningococcal (MenB) vaccine should not be given during pregnancy, as there is not enough information about the potential risks of this vaccine during pregnancy or during the postpartum period for breastfeeding women [24].

\section{Safety of Antiretroviral Agents during Pregnancy}

The most effective method of identifying adverse fetal/ neonatal outcomes is to report all drug exposures to the
Antiretroviral Pregnancy Registry [25]. The information needed to participate in this registry can be readily located online at http://www.apregistry.com/. Table 2 illustrates the different treatment regimens by class for HIV-Infected pregnant women, while Table 3 illustrates the most common reported adverse pregnancy outcomes of certain ARVs.

Small cohort studies have raised the concern that ARVs during pregnancy were associated with low birth weight and preterm birth [26-29], while these concerns may be in fact due to the severity of the disease, rather than the association with ARVs [30]. Other studies have evaluated the use of protease inhibitors and the risk of preterm delivery (PTD) [31-34], as well as the use of zidovudine and the risk of congenital cardiac defects [35], while others have shown favorable pregnancy outcomes [36].

Specific ARV regimens from HIV-pregnant women who gave birth to HIV exposed HIV negative infants have been 
TABLE 3: Pregnancy outcomes of individual antiretroviral agents during pregnancy* .

\begin{tabular}{|c|c|c|}
\hline \multirow{2}{*}{ Brand name } & \multicolumn{2}{|c|}{ Reported adverse pregnancy outcomes } \\
\hline & Maternal & Fetal/neonatal \\
\hline \multicolumn{3}{|c|}{ NRTI } \\
\hline Zidovudine & $\begin{array}{l}\text { Potential for hematologic toxicities } \\
\text { (anemia and bone marrow suppression) } \\
\text { [52], including elevated liver function } \\
\text { tests [53], myelotoxicity [54], acute } \\
\text { pancreatitis [54], preeclampsia, and other } \\
\text { hypertensive disorders [55] }\end{array}$ & $\begin{array}{l}\text { PTD [37], SGA [37], LBW [37], and CHD } \\
\text { [35] }\end{array}$ \\
\hline Tenofovir disoproxil fumarate & Kidney [56] and bone toxicity [57] & $\begin{array}{l}\text { Decreased bone mineral density content } \\
\text { [58] }\end{array}$ \\
\hline \multicolumn{3}{|c|}{ NNRTI } \\
\hline Efavirenz & Rash and drug interactions [59] & $\begin{array}{l}\text { Initial concern of birth defects seen in } \\
\text { primate study [60]; however, recent } \\
\text { studies have not shown an increased risk } \\
\text { of neural tube defects [61] }\end{array}$ \\
\hline Abacavir & $\begin{array}{l}\text { Abacavir should not be used in patients } \\
\text { who test positive for HLA-B } 5701 \\
\text { because a positive test may increase the } \\
\text { risk of a hypersensitivity reaction [56], } \\
\text { nausea, vomiting, diarrhea, and } \\
\text { abdominal pain [59] }\end{array}$ & None \\
\hline Didanosine & $\begin{array}{l}\text { Pancreatitis (acute and chronic) [54] and } \\
\text { neuropathy }\end{array}$ & $\begin{array}{l}\text { Initial studies concerning for an } \\
\text { association with fetal anomalies, } \\
\text { specifically head and neck anomalies } \\
\text { when exposed during the first trimester } \\
\text { [35]; however, recent studies found no } \\
\text { adverse outcomes [62] }\end{array}$ \\
\hline Nevirapine & $\begin{array}{l}10 \text {-fold increased risk of hepatotoxicity } \\
{[63,64]}\end{array}$ & No reported fetal malformations [64] \\
\hline Emtricitabine & $\begin{array}{l}\text { Headache, nausea, vomiting, and } \\
\text { diarrhea [59] }\end{array}$ & None [65] \\
\hline \multicolumn{3}{|c|}{ Protease inhibitors } \\
\hline Ritonavir & $\begin{array}{l}\text { Nausea, vomiting, increased triglycerides, } \\
\text { and transaminases [59] }\end{array}$ & \\
\hline Atazanavir & $\begin{array}{l}\text { Abdominal pain, diarrhea, nausea, and } \\
\text { increased liver function tests [59] }\end{array}$ & PTD $[31,32,34,66]$ \\
\hline Lopinavir & $\begin{array}{l}\text { Nausea, vomiting, diarrhea, and } \\
\text { pancreatitis [59] }\end{array}$ & PTD $[21,31,34,66]$ \\
\hline Darunavir & $\begin{array}{l}\text { Maternal hyperbilirubinemia and nausea } \\
\text { [59] }\end{array}$ & PTD $[31,32,34,66]$ \\
\hline
\end{tabular}

* Table provides a short list of the updated ARV's and their reported safety issues.

${ }^{¥}$ Nevirapine can cause fatal and severe hepatotoxicity among women with CD4 lymphocytes $>250 \mathrm{cells} / \mu \mathrm{L}$.

NRTI: nucleoside or nucleotide reverse transcriptase inhibitor, NNRTI: nonnucleoside or nonnucleotide reverse transcriptase inhibitor, PTD: preterm delivery (delivery prior to 37 weeks), SGA: small for gestational age (birth weight less than the 10th percentile for their gestational age), LBW: low birth weight (birth weight less than 2500 grams), and CHD: congenital heart defects.

evaluated from a large cohort in sub-Sahara Africa of more than 3000 patients for their association with adverse pregnancy outcomes, specifically for PTD, small for gestational age (SGA), and low birth weight (LBW) $[37,38]$ in relation to the duration of ARV exposure. The authors noted a $30 \%$ increased risk of preterm delivery amongst infants ARV-exposed women, with the highest risk in women who initiated ARVs prior to conception, compared to those who initiated ARVs during pregnancy or received zidovudine monotherapy [37]. Similarly, there was a $20 \%$ increased risk of infants being diagnosed with SGA when exposed to ARVs during pregnancy and before conception; however, when they assessed different ARV exposures, there was no difference in the overall SGA neonates [37].

The highest rates of PTD (25\%) and SGA (13\%) were those women treated with protease inhibitors during pregnancy [37]. They also found an increased likelihood of LBW amongst women who initiated ARVs prior to conception and those who were exposed to ARVs during pregnancy. Overall, they found that pregnant women exposed to ARVs of longer 
duration with initiation of ARVs prior to pregnancy had the highest rates of PTD, SGA, and LBW [37]. It is unclear the exact mechanism of why these adverse pregnancy outcomes were seen $[39,40]$, and further comparative evaluations of different regimens are needed.

Intrapartum, maternal infusion of zidovudine dosing has been investigated and compared to therapeutic exposures in order to assess fetal concentrations [41]. Reducing the maternal infusion dosage from a loading dose of $2 \mathrm{mg} / \mathrm{kg}$ to $1 \mathrm{mg} / \mathrm{kg}$ over 1 hour, followed by a reduction in the maintenance dosage of $1 \mathrm{mg} / \mathrm{kg}$ to $0.5 \mathrm{mg} / \mathrm{kg}$ each hour until delivery, reduced fetal exposures [41]. This can also be achieved by taking zidovudine orally every 5 hours, starting at the onset of labor until the time of delivery, followed by neonatal zidovudine prophylaxis as soon as possible after birth [41]. This reduction in zidovudine dosage during the first few days of neonatal life also is important as well.

While treatment of HIV during pregnancy is crucial and the benefits outweigh the risks for the prevention of MTCT, the safety profile of ARVs during pregnancy has shown conflicting evidence. It is ideal that medical providers caring for HIV infected reproductive age women start ARVs prior to pregnancy and continue these throughout pregnancy, or as early as tolerated during pregnancy to achieve the ultimate goal of viral suppression and prevention of MTCT.

\section{Postpartum Care}

All HIV-infected women should have a routine postpartum follow-up visit with their obstetric provider. After delivery, establishing retention in HIV care is critical, with referral to an infectious disease specialist. Counseling patients regarding adherence to CART, irrespective of CD4 count, is very important, as some HIV-infected women become noncompliant with cART during follow-up after delivery.

Future efforts should be geared towards adapting new strategies in the US to achieve postpartum retention in HIV care settings [42], particularly because there are a limited number of available published reports addressing these strategies during the postpartum period. These strategies include discussion about unintended pregnancy prevention with contraceptive counseling, as well as HIV/STD preventive strategies such as consistent condom use and preexposure prophylaxis. In addition, similar to the preconceptioncounseling period, postpartum counseling should address intimate partner violence, postpartum depression, and other mental health issues that require treatment, as well as providing linkage to intimate partner violence services [43, 44].

\section{Infant Follow-Up and Postnatal Prophylaxis}

Regardless of maternal viral load, after birth, all babies born to HIV-infected women should be bathed immediately to remove any potentially infectious maternal secretions [18]. Baseline complete blood counts and HIV diagnostic testing by HIV DNA PCR are to establish or rule out HIV infection, followed by ZDV prophylaxis. Within 12 hours after birth, and ideally no later than 24 hours, all neonates born to HIV positive mothers should receive a course of $\mathrm{ZDV}$ therapy, which will be continued for 6 weeks in the US; however, a 4week regimen can be considered for full-term infants whose mothers had maintained HIV viral suppression antenatally $[45,46]$.

A recent study evaluated three postpartum cART regimens for neonates born to mothers infected with HIV who have not received any antepartum cART or had a viral load of $>1,000$ copies/mL near the time of delivery [47]. Combination prophylaxis with either a 2-drug (zidovudine plus nevirapine) regimen or a 3-drug regimen (zidovudine plus nelfinavir and lamivudine) was found to have superior efficacy, when compared to zidovudine monotherapy alone, with significantly reduced transmission rates of HIV [47]. The Department of Health and Human Services (DHHS) for the US currently recommends that at least 3 doses of nevirapine within the first 7 days of life be administered, in addition to ZDV therapy as prophylaxis during high-risk perinatal exposure when maternal HIV viral load is or is assumed to be more than 1,000 copies $/ \mathrm{mL}$.

Premastication of food for infants of HIV-infected mothers should be avoided, as this can potentiate the risk of HIV transmission [48]. Free clinical perinatal HIV consultation, including the care of an HIV-exposed neonate, is available for medical providers at The National Perinatal HIV Hotline at 1888-448-8765.

Although early-term deliveries can be associated with increased neonatal intensive care unit admissions and higher hospital costs, when compared to those beyond 39 weeks [49], the recommendations currently endorsed by the American College of Obstetricians and Gynecologists (ACOG) is for cesarean deliveries at 38 weeks for pregnant women with HIV-1 RNA viral loads $>1,000$ copies/mL [50]. We currently recommend delivery prior to 39 weeks of gestation for other high-risk conditions if the benefit of earlier delivery outweighs the risk of expectant management; therefore, decreasing the risk of spontaneous labor/rupture of membranes between 38 to 39 weeks in women with an HIV-1 RNA viral loads $>1,000$ copies/mL outweighs very small increased transient risks of delivery at 38 versus 39 weeks for the neonate [51].

\section{Summary of Future Potential Practices}

(i) It is ideal that medical providers caring for HIV infected reproductive age women start ARVs prior to pregnancy and continue these throughout pregnancy, or as early as tolerated during pregnancy to achieve the ultimate goal of viral suppression and prevention of MTCT.

(ii) During the preconception counseling and postpartum periods, medical providers should identify women who may be victims of intimate partner violence, depression, and other psychological or psychiatric illnesses that may serve as barriers to prevention of MTCT and to treat and gain control of these conditions prior to contemplating pregnancy. 
(iii) These strategies not only will result in safer conception and better compliance with cART but also will result in better pregnancy outcomes and less adverse pregnancy outcomes, as these patients will be more compliant with their prenatal visits and follow recommendations outlined by their obstetrical provider.

(iv) Prevention of pitfalls and missed opportunities in healthcare delivery can be achieved by medical providers screening all pregnant women for HIV, ideally in the first trimester or at their first prenatal visit, establishing an early diagnosis of $\mathrm{HIV}$ and initiating cART early in the pregnancy.

(v) Postpartum retention in HIV care settings is critical and can best be achieved through strategies that include a discussion about future unintended pregnancies with contraceptive counseling, as well as preventive strategies such as consistent condom use and preexposure prophylaxis.

\section{Competing Interests}

Rana Chakraborty is supported by the NICHD IMPAACT Network (HHSN275701300003C), by the CDC (1U01PS003322-01), by the NIH (5R01AA018096), and by the CDC Grant (5U48DP001909-04). Lisa Haddad is supported by the NICHD (1K23HD078153-01A1). Martina L. Badell NICHD is supported by IMPAACT Network (HHSN275701300003C). Bassam H. Rimawi reports no competing interests.

\section{Acknowledgments}

Rana Chakraborty has received research support from Gilead.

\section{References}

[1] Center for Disease Control and Prevention (CDC), HIV among Pregnant Women, Infants, and Children in the United States, CDC, Atlanta, Ga, USA, 2012.

[2] A. P. Kourtis, F. K. Lee, E. J. Abrams, D. J. Jamieson, and M. Bulterys, "Mother-to-child transmission of HIV-1: timing and implications for prevention," The Lancet Infectious Diseases, vol. 6, no. 11, pp. 726-732, 2006.

[3] J. P. A. Ioannidis, E. J. Abrams, A. Ammann et al., "Perinatal transmission of human immunodeficiency virus type 1 by pregnant women with RNA virus loads <1000 copies/mL," Journal of Infectious Diseases, vol. 183, no. 4, pp. 539-545, 2001.

[4] L. Mandelbrot, J. Le Chenadec, A. Berrebi et al., "Perinatal HIV1 transmission: interaction between zidovudine prophylaxis and mode of delivery in the French perinatal cohort," The Journal of the American Medical Association, vol. 280, no. 1, pp. 55-60, 1998.

[5] "The mode of delivery and the risk of vertical transmission of human immunodeficiency virus type 1-a meta-analysis of 15 prospective cohort studies. The International Perinatal HIV Group," The New England Journal of Medicine, vol. 340, no. 13, pp. 977-987, 1999.
[6] J. Jean, A. Coll, M. Monda, J. Potter, and D. Jones, "Perspectives on safer conception practices and preconception counseling among women living with HIV," Health Care for Women International, 2015.

[7] A. F. Camacho-Gonzalez, M.-H. Kingbo, A. Boylan, A. R. Eckard, A. Chahroudi, and R. Chakraborty, "Missed opportunities for prevention of mother-to-child transmission in the United States," AIDS, vol. 29, no. 12, pp. 1511-1515, 2015.

[8] S. Nesheim, L. F. Harris, and M. Lampe, "Elimination of perinatal HIV infection in the USA and other high-income countries: achievements and challenges," Current Opinion in HIV \& AIDS, vol. 8, no. 5, pp. 447-456, 2013.

[9] S. Nesheim, A. Taylor, M. A. Lampe et al., "A framework for elimination of perinatal transmission of HIV in the United States," Pediatrics, vol. 130, no. 4, pp. 738-744, 2012.

[10] A. S. Coll, J. E. Potter, N. Chakhtoura, M. L. Alcaide, R. Cook, and D. L. Jones, "Providers' perspectives on preconception counseling and safer conception for HIV-infected women," AIDS Care, vol. 28, no. 4, pp. 513-518, 2016.

[11] S. Chaithongwongwatthana, "Conceptive options for people living with HIV," Journal of the Medical Association of Thailand, vol. 98, supplement 1, pp. S123-S126, 2015.

[12] M. V. Sauer, "Sperm washing techniques address the fertility needs of HIV-seropositive men: a clinical review," Reproductive BioMedicine Online, vol. 10, no. 1, pp. 135-140, 2005.

[13] G. C. Jayaraman, J. K. Preiksaitis, and B. Larke, "Mandatory reporting of HIV infection and opt-out prenatal screening for HIV infection: effect on testing rates," Canadian Medical Association Journal, vol. 168, no. 6, pp. 679-682, 2003.

[14] "Committee opinion no: 635: prenatal and perinatal human immunodeficiency virus testing: expanded recommendations," Obstetrics \& Gynecology, vol. 125, no. 6, pp. 1544-1547, 2015.

[15] M. Bulterys, D. J. Jamieson, M. J. O’Sullivan et al., "Rapid HIV1 testing during labor: a multicenter study," The Journal of the American Medical Association, vol. 292, no. 2, pp. 219-223, 2004.

[16] ACOG Committee on Obstetric Practice, "ACOG committee opinion number 304, November 2004. Prenatal and perinatal human immunodeficiency virus testing: expanded recommendations," Obstetrics \& Gynecology, vol. 104, no. 5, part 1, pp. 1119$1124,2004$.

[17] B. Weber, R. Thorstensson, S. Tanprasert, U. Schmitt, and W. Melchior, "Reduction of the diagnostic window in three cases of human immunodeficiency-1 subtype E primary infection with fourth-generation HIV screening assays," Vox Sanguinis, vol. 85, no. 2, pp. 73-79, 2003.

[18] P. L. Havens, R. Chakraborty, E. Cooper et al., "HIV testing and prophylaxis to prevent mother-to-child transmission in the united states," Pediatrics, vol. 122, no. 5, pp. 1127-1134, 2008.

[19] N. M. Doyle, J. E. Levison, and M. O. Gardner, "Rapid HIV versus enzyme-linked immunosorbent assay screening in a low-risk Mexican American population presenting in labor: a cost-effectiveness analysis," American Journal of Obstetrics and Gynecology, vol. 193, no. 3, part 2, pp. 1280-1285, 2005.

[20] Centers for Disease Control and Prevention, "Revised classification system for HIV infection and expanded surveillance case definition for AIDS among adolescents and adults," The Journal of the American Medical Association, vol. 269, no. 6, pp. 729-730, 1993.

[21] M. W. F. Rac and J. S. Sheffield, "Prevention and management of viral hepatitis in pregnancy," Obstetrics and Gynecology Clinics of North America, vol. 41, no. 4, pp. 573-592, 2014. 
[22] R. S. Brown Jr., B. J. McMahon, A. S. F. Lok et al., "Antiviral therapy in chronic hepatitis B viral infection during pregnancy: a systematic review and meta-analysis," Hepatology, vol. 63, no. 1, pp. 319-333, 2016.

[23] J. Dionne-Odom, A. T. N. Tita, and N. S. Silverman, "Hepatitis $\mathrm{B}$ in pregnancy screening, treatment, and prevention of vertical transmission," American Journal of Obstetrics and Gynecology, vol. 214, no. 1, pp. 6-14, 2016.

[24] Advisory Committee on Immunization Practices Centers for Disease Control and Prevention, "Guiding principles for development of ACIP recommendations for vaccination during pregnancy and breastfeeding," Morbidity and Mortality Weekly Report, vol. 57, no. 21, p. 580, 2008.

[25] A. D. White and E. B. Andrews, "The pregnancy registry program at glaxo wellcome company," Journal of Allergy and Clinical Immunology, vol. 103, no. 2, pp. S362-S363, 1999.

[26] J. Y. Chen, H. J. Ribaudo, S. Souda et al., "Highly active antiretroviral therapy and adverse birth outcomes among HIVinfected women in Botswana," The Journal of Infectious Diseases, vol. 206, no. 11, pp. 1695-1705, 2012.

[27] L. Yu, W.-Y. Li, R. Y. Chen et al., "Pregnancy outcomes and risk factors for low birth weight and preterm delivery among HIVinfected pregnant women in Guangxi, China," Chinese Medical Journal, vol. 125, no. 3, pp. 403-409, 2012.

[28] F. Martin and G. P. Taylor, "Increased rates of preterm delivery are associated with the initiation of highly active antiretrovial therapy during pregnancy: a single-center cohort study," Journal of Infectious Diseases, vol. 196, no. 4, pp. 558-561, 2007.

[29] M. Lopez, F. Figueras, S. Hernandez et al., "Association of HIV infection with spontaneous and iatrogenic preterm delivery: effect of HAART," AIDS, vol. 26, no. 1, pp. 37-43, 2012.

[30] E. Aaron, A. Bonacquisti, L. Mathew, G. Alleyne, L. P. Bamford, and J. F. Culhane, "Small-for-gestational-age births in pregnant women with HIV, due to severity of HIV disease, not antiretroviral therapy," Infectious Diseases in Obstetrics and Gynecology, vol. 2012, Article ID 135030, 9 pages, 2012.

[31] J. Sibiude, J. Warszawski, R. Tubiana et al., "Premature delivery in HIV-infected women starting protease inhibitor therapy during pregnancy: role of the ritonavir boost?" Clinical Infectious Diseases, vol. 54, no. 9, pp. 1348-1360, 2012.

[32] H. Minkoff and M. Augenbraun, "Antiretroviral therapy for pregnant women," American Journal of Obstetrics and Gynecology, vol. 176, no. 2, pp. 478-489, 1997.

[33] A. B. Morris, A. R. Dobles, S. Cu-Uvin et al., "Protease inhibitor use in 233 pregnancies," Journal of Acquired Immune Deficiency Syndromes, vol. 40, no. 1, pp. 30-33, 2005.

[34] A. M. Cotter, A. G. Garcia, M. L. Duthely, B. Luke, and M. J. O’Sullivan, "Is antiretroviral therapy during pregnancy associated with an increased risk of preterm delivery, low birth weight, or stillbirth?" Journal of Infectious Diseases, vol. 193, no. 9, pp. 1195-1201, 2006.

[35] J. Sibiude, L. Mandelbrot, S. Blanche et al., "Association between prenatal exposure to antiretroviral therapy and birth defects: an analysis of the French perinatal cohort study (ANRS CO1/CO11)," PLoS Medicine, vol. 11, no. 4, Article ID e1001635, 2014.

[36] M. C. Marazzi, L. Palombi, K. Nielsen-Saines et al., "Extended antenatal use of triple antiretroviral therapy for prevention of mother-to-child transmission of HIV-1 correlates with favorable pregnancy outcomes," AIDS, vol. 25, no. 13, pp. 1611-1618, 2011.
[37] N. Li, M. M. Sando, D. Spiegelman et al., "Antiretroviral therapy in relation to birth outcomes among HIV-infected Women: a cohort study," Journal of Infectious Diseases, vol. 213, no. 7, pp. 1057-1064, 2016.

[38] L. Mofenson, "Antiretroviral therapy and adverse pregnancy outcome: the elephant in the room?" Journal of Infectious Diseases, vol. 213, no. 7, pp. 1051-1054, 2016.

[39] K. M. Powis and R. L. Shapiro, "Protease inhibitors and adverse birth outcomes: is progesterone the missing piece to the puzzle?" The Journal of Infectious Diseases, vol. 211, no. 1, pp. 4-7, 2015.

[40] S. Fiore, M.-L. Newell, D. Trabattoni et al., "Antiretroviral therapy-associated modulation of Th1 and Th2 immune responses in HIV-infected pregnant women," Journal of Reproductive Immunology, vol. 70, no. 1-2, pp. 143-150, 2006.

[41] F. Fauchet, J.-M. Treluyer, E. Valade et al., "Maternal and fetal zidovudine pharmacokinetics during pregnancy and labour: too high dose infused at labour?" British Journal of Clinical Pharmacology, vol. 78, no. 6, pp. 1387-1396, 2014.

[42] M. K. Buchberg, F. E. Fletcher, D. J. Vidrine et al., "A mixedmethods approach to understanding barriers to postpartum retention in care among low-income, HIV-infected women," AIDS Patient Care and STDs, vol. 29, no. 3, pp. 126-132, 2015.

[43] L. H. Rubin, J. A. Cook, D. D. Grey et al., "Perinatal depressive symptoms in HIV-infected versus HIV-uninfected women: a prospective study from preconception to postpartum," Journal of Women's Health, vol. 20, no. 9, pp. 1287-1295, 2011.

[44] J. R. Ickovics, M. E. Hamburger, D. Vlahov et al., "Mortality, CD4 cell count decline, and depressive symptoms among HIV-seropositive women: longitudinal analysis from the HIV epidemiology research study," The Journal of the American Medical Association, vol. 285, no. 11, pp. 1466-1474, 2001.

[45] J. Neubert, M. Pfeffer, A. Borkhardt et al., "Risk adapted transmission prophylaxis to prevent vertical HIV-1 transmission: effectiveness and safety of an abbreviated regimen of postnatal oral Zidovudine," BMC Pregnancy and Childbirth, vol. 13, article 22, 2013.

[46] W. Ferguson, M. Goode, A. Walsh, P. Gavin, and K. Butler, "Evaluation of 4 weeks' neonatal antiretroviral prophylaxis as a component of a prevention of mother-to-child transmission program in a resource-rich setting," Pediatric Infectious Disease Journal, vol. 30, no. 5, pp. 408-412, 2011.

[47] K. Nielsen-Saines, D. H. Watts, V. G. Veloso et al., "Three postpartum antiretroviral regimens to prevent intrapartum HIV infection," The New England Journal of Medicine, vol. 366, no. 25, pp. 2368-2379, 2012.

[48] W. E. Ivy III, K. L. Dominguez, N. Y. Rakhmanina et al., "Premastication as a route of pediatric HIV transmission: casecontrol and cross-sectional investigations," Journal of Acquired Immune Deficiency Syndromes, vol. 59, no. 2, pp. 207-212, 2012.

[49] D. M. Ashton, "Elective delivery at less than 39 weeks," Current Opinion in Obstetrics and Gynecology, vol. 22, no. 6, pp. 506-510, 2010.

[50] Committee on Obstetric Practice, "ACOG committee opinionscheduled cesarean delivery and the prevention of vertical transmission of HIV infection," International Journal of Gynecology \& Obstetrics, vol. 73, no. 3, pp. 279-281, 2001.

[51] A. R. Fleischman, M. Oinuma, and S. L. Clark, "Rethinking the definition of 'term pregnancy"' Obstetrics and Gynecology, vol. 116, no. 1, pp. 136-139, 2010. 
[52] "Erythropoietin for zidovudine-induced anemia," The New England Journal of Medicine, vol. 323, no. 15, pp. 1069-1070, 1990.

[53] T. J. Nagu, M. Kanyangarara, C. Hawkins et al., "Elevated alanine aminotransferase in antiretroviral-naïve HIV-infected African patients: magnitude and risk factors," HIV Medicine, vol. 13, no. 9, pp. 541-548, 2012.

[54] N. M. E. Oliveira, F. A. U. Y. Ferreira, R. Y. U. Yonamine, and E. Z. I. Chehter, "Antiretroviral drugs and acute pancreatitis in HIV/AIDS patients: is there any association? A literature review," Einstein, vol. 12, no. 1, pp. 112-119, 2014.

[55] R. C. Wimalasundera, N. Larbalestier, J. H. Smith et al., "Preeclampsia, antiretroviral therapy, and immune reconstitution," The Lancet, vol. 360, no. 9340, pp. 1152-1154, 2002.

[56] M. Mirochnick and E. Capparelli, "Pharmacokinetics of antiretrovirals in pregnant women," Clinical Pharmacokinetics, vol. 43, no. 15, pp. 1071-1087, 2004.

[57] E. De Clercq, "Tenofovir alafenamide (TAF) as the successor of tenofovir disoproxil fumarate (TDF)," Biochemical Pharmacology, 2016.

[58] G. K. Siberry, D. L. Jacobson, H. J. Kalkwarf et al., "Lower newborn bone mineral content associated with maternal use of tenofovir disoproxil fumarate during pregnancy," Clinical Infectious Diseases, vol. 61, no. 6, pp. 996-1003, 2015.

[59] R. A. Murphy, H. Sunpath, D. R. Kuritzkes, F. Venter, and R. T. Gandhi, "Antiretroviral therapy-associated toxicities in the resource-poor world: the challenge of a limited formulary," Journal of Infectious Diseases, vol. 196, supplement 3, pp. S449S456, 2007.

[60] H. Bussmann, C. W. Wester, C. N. Wester et al., "Pregnancy rates and birth outcomes among women on efavirenz-containing highly active antiretroviral therapy in Botswana," Journal of Acquired Immune Deficiency Syndromes, vol. 45, no. 3, pp. 269273, 2007.

[61] N. Ford, L. Mofenson, Z. Shubber et al., "Safety of efavirenz in the first trimester of pregnancy: an updated systematic review and meta-analysis," AIDS, vol. 28, supplement 2, pp. S123-S131, 2014.

[62] P. L. Williams, M. J. Crain, C. Yildirim et al., "Congenital anomalies and in utero antiretroviral exposure in human immunodeficiency virus-exposed uninfected infants," JAMA Pediatrics, vol. 169, no. 1, pp. 48-55, 2015.

[63] M. S. Baylor and R. Johann-Liang, "Hepatotoxicity associated with nevirapine use," Journal of Acquired Immune Deficiency Syndromes, vol. 35, no. 5, pp. 538-539, 2004.

[64] R. Manfredi and L. Calza, "Safety issues about nevirapine administration in HIV-infected pregnant women," Journal of Acquired Immune Deficiency Syndromes, vol. 45, no. 3, pp. 365368, 2007.

[65] Antiretroviral Pregnancy Registry Steering Committee, Antiretroviral Pregnancy Registry International Interim Report for 1989-2014, Registry Coordinating Center, Wilmington, NC, USA, 2014, http://www.APRegistry.com/.

[66] K. Morris, "Short course of AZT halves HIV-1 perinatal transmission," The Lancet, vol. 351, no. 9103, p. 651, 1998. 


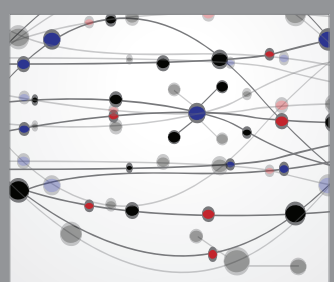

The Scientific World Journal
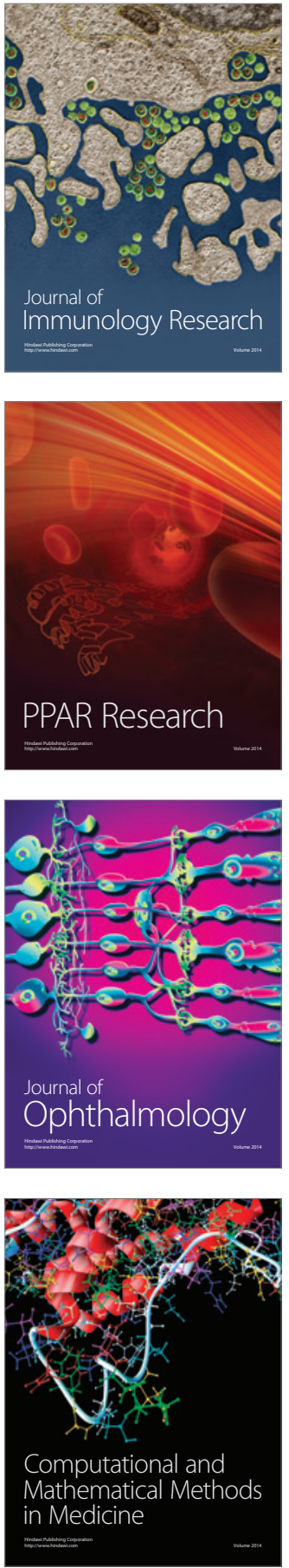

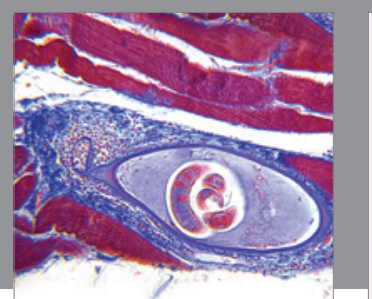

Gastroenterology Research and Practice

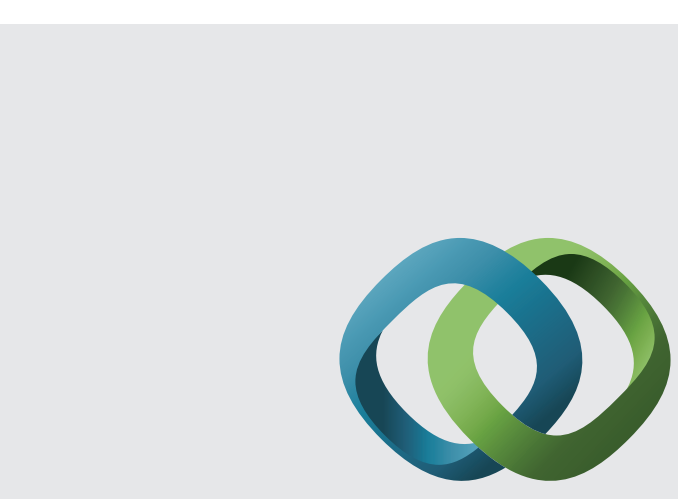

\section{Hindawi}

Submit your manuscripts at

http://www.hindawi.com
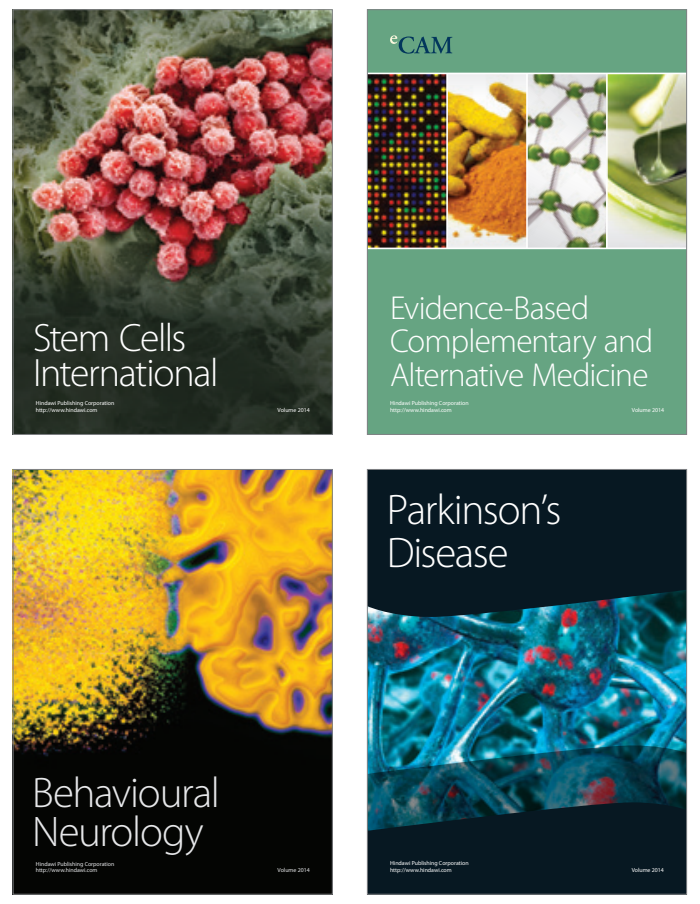
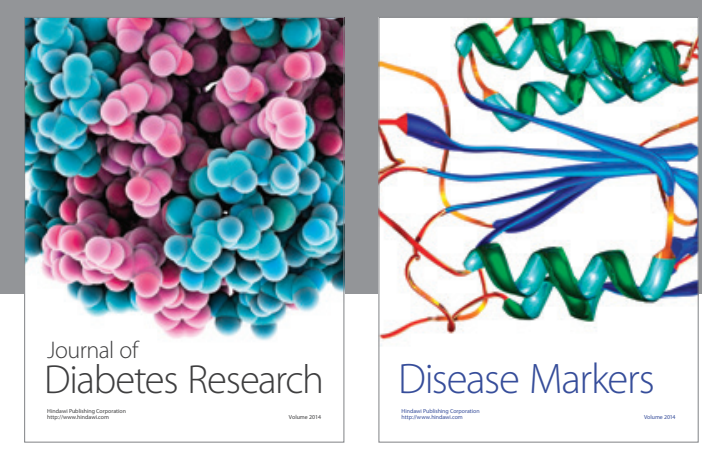

Disease Markers
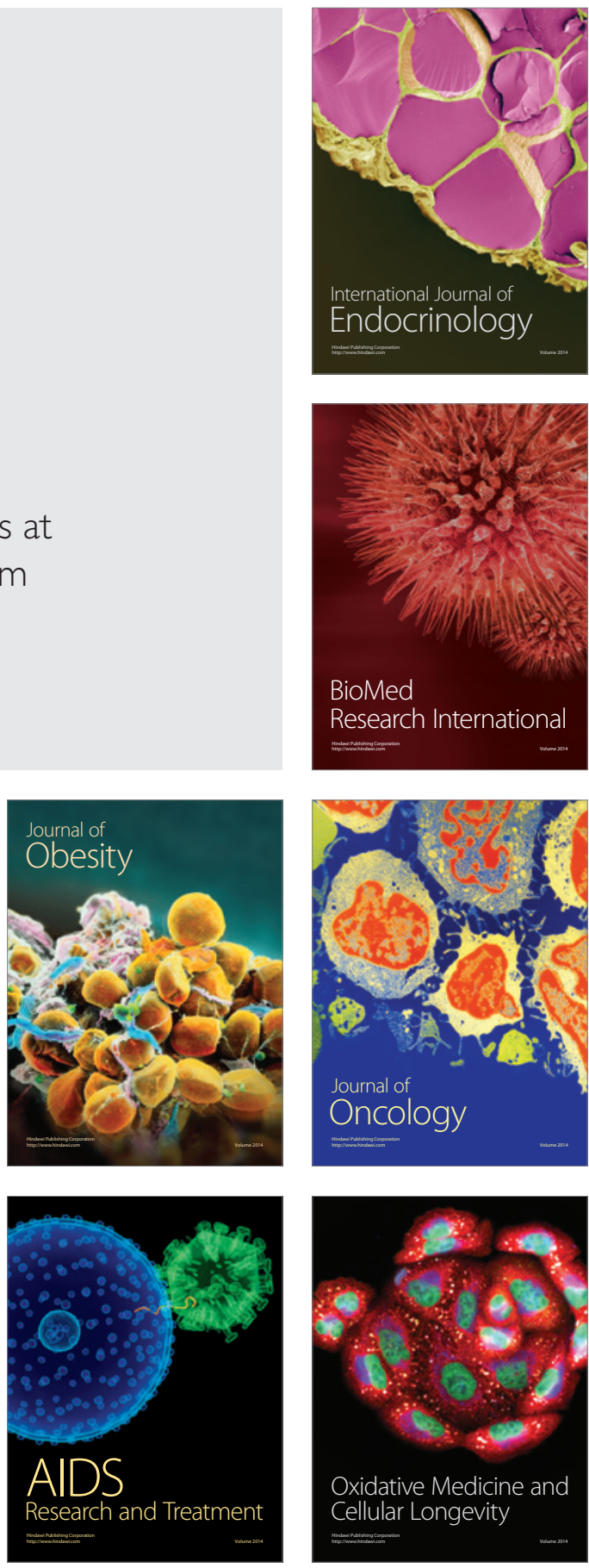